\title{
Phytotoxicity of silver nanoparticles (AgNPs) prepared by green synthesis using sage leaves (Salvia officinalis).
}

\author{
GARGULAK, M., HOSNEDLOVA, B., KEPINSKA, M., STROFOVA, N., \\ DOCEKALOVA, M., MILNEROWICZ, H., SEHNAL, K., OFOMAJA, A.E., \\ FERNANDEZ, C., SOCHOR, J., KIZEK, R.
} uses, in any current or future media, including reprinting/republishing this material for advertising or promotional purposes, creating new collective works, for resale or redistribution to servers or lists, or reuse of any copyrighted component of this work in other works. 


\title{
Phytotoxicity of silver nanoparticles (AgNPs) prepared by green synthesis
}

\section{using sage leaves (Salvia officinalis)}

\author{
Michael Gargulak \\ Department of Human Pharmacology and Toxicology, Faculty of Pharmacy, University of Veterinary and Pharmaceutical \\ Sciences Brno, Palackeho 1946/1, \\ 61242 Brno, Czech Republic \\ michaelgargulak@seznam.cz \\ Karel Sehnal \\ Institute of Viticulture and Wine Production, Faculty of Horticulture, Valtická 337 \\ 69144 Lednice, Czech Republic \\ karelsehnal15@gmail.com \\ Bozena Hosnedlova \\ Institute of Viticulture and Wine Production, Faculty of Horticulture, Valtická 337 \\ 69144 Lednice, Czech Republic \\ bozena.hosnedlova@post.cz \\ Michaela Docekalova \\ Department of Research and Development, Prevention Medicals, Továrni 342, 742 13, \\ Studénka-Butovice, Czech Republic, \\ docekalova@preventionmedicals.cz
Augustine Enakpodia Ofomaja
Sciences, Vaal University of Technology, P. Bag X021,
Vanderbijlpark, 1900, South Africa,
augustineo@vut.ac.za \\ Biosorption and Wastewater Treatment Research Laboratory, Department of Chemistry, Faculty of Applied and Computer \\ Nikola Strofova \\ Department of Human Pharmacology and Toxicology, Faculty of Pharmacy, University of Veterinary and Pharmaceutical \\ Sciences Brno, Palackeho 1946/1, \\ 61242 Brno, Czech Republic \\ Nikola.Strofova@seznam.cz \\ Marta Kepinska \\ Department of Biomedical and Environmental Analyses, Faculty of Pharmacy with Division of Laboratory Medicine, \\ Wroclaw Medical University, Borowska 211, \\ 50-556 Wroclaw, Poland \\ zalewska@gmail.cz \\ Halina Milnerowicz \\ Department of Biomedical and Environmental Analyses, Faculty of Pharmacy with Division of Laboratory Medicine, \\ Wroclaw Medical University, Borowska 211, \\ 50-556 Wroclaw, Poland \\ zalewska@gmail.cz \\ Carlos Fernandez \\ School of Pharmacy and Life Sciences, Robert Gordon University, Garthdee Road, \\ Aberdeen AB10 7QB, United Kingdom \\ c.fernandez@rgu.ac.uk

\section{Jiri Sochor} \\ Institute of Viticulture and Wine Production, Faculty of Horticulture, Valtická 337 \\ 69144 Lednice, Czech Republic \\ sochor@mendelu.cz \\ Rene Kizek \\ Institute of Viticulture and Wine Production, Faculty of Horticulture, Valtická 337 \\ 69144 Lednice, Czech Republic \\ kizek@sci.muni.cz
}


Abstract - Silver nanoparticles are widely investigated with regard to their physical, chemical, but also biological properties. Antibacterial and antitumor properties of AgNPs have been intensively studied. In addition, the synthesis using a green approach brings further significant biological properties. However, it is also necessary to monitor the potential toxicity of such nanoparticles in different ecosystems. In this experiment, the effect of $\mathrm{AgNO}_{3}$ and AgNPs on germinated plants of Zea mays was studied. Effects on basic growth and physiological parameters were observed. There was a statistically significant difference between the variants tested.

Keywords - green synthesis, antibacterial material, electrochemistry, phytotoxicity, phyto-nanotechnology

\section{Introduction}

In the current decade, nanomaterials (NPs) are intensively investigated. The knowledge about their toxicity and behavior in eco-environment is very important $[1,2]$. Silver nanoparticles are defined as individual silver particles or small silver aggregates with a size of 1-100 $\mathrm{nm}$ [3-5]. Due to their small size, large surface capacity and antimicrobial effects, they are widely used in many industries including electronics, medical diagnostics, textile industry, or also in personal care [6]. Biological synthesis of nanoparticles using plants and microorganisms has been described in a previous review paper [7, 8] and is still given great attention [9].

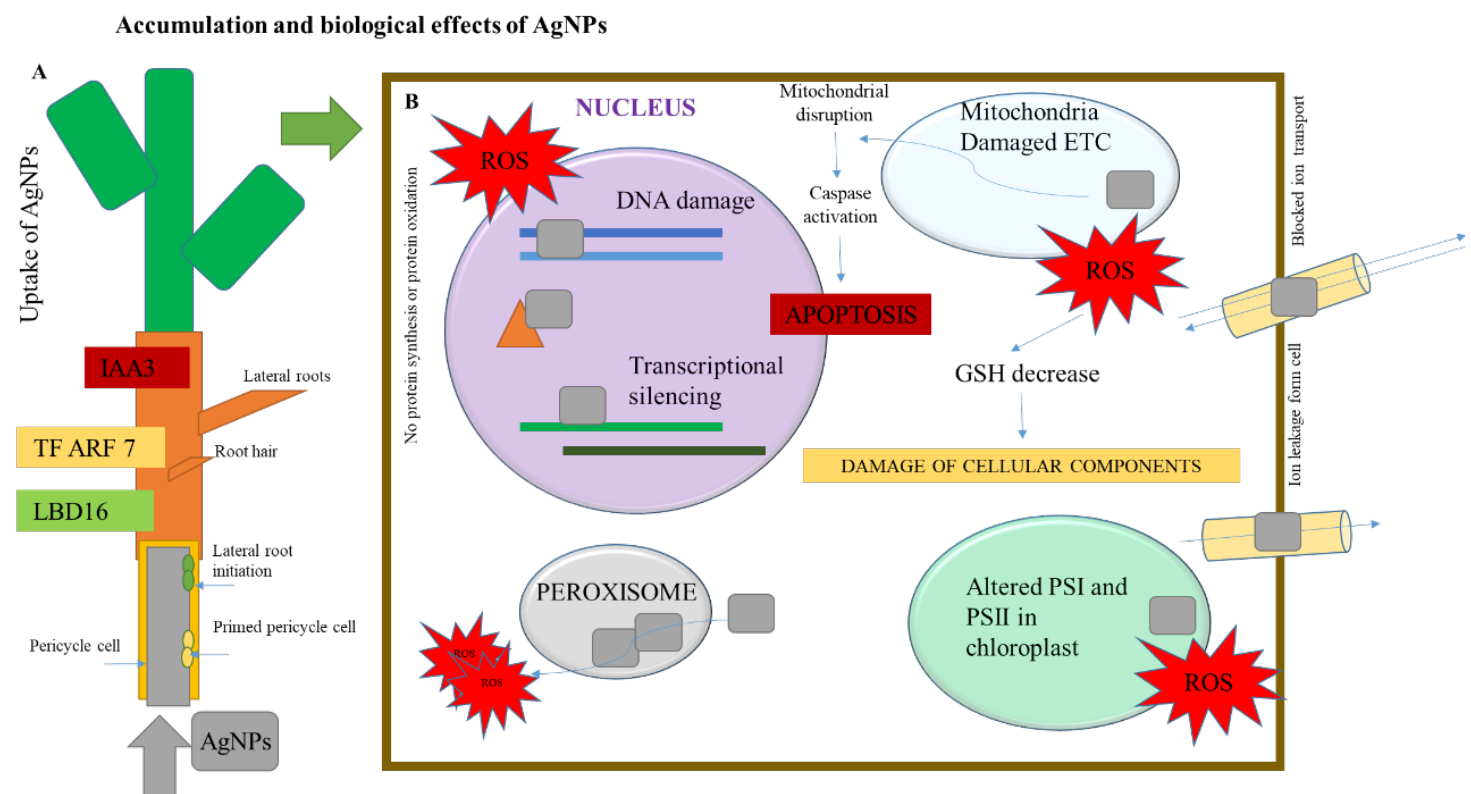


Fig. 1. The expected biological effects of AgNPs on plants. (A) The soil particles are surrounded by water potential gradients that affect plant root growth (due to positive hydrotropism, the growth of the roots is directed towards the water) and thus also the nutrient intake. Hydropatterning changes the distribution of root hairs and lateral roots along the root circumference. It has recently been discovered that the transcription factor ARF7 activates the LDB16 gene, which induced the initiation of lateral roots formation when water is available. These recent molecular findings can bring new information on the NPs [10]. (B) AgNPs enter the plant through conductive elements and are transported to its organs and cells. AgNPs induce reactive oxygen species (ROS) formation and distinct reactions in peroxisomes in the cells. The most important predicted effects of AgNPs phytotoxicity on the nucleus (DNA damage, transcription factor binding, etc.), mitochondria (e.g., respiratory chain damage, damage to DNA and membranes), chloroplast (e.g., damage to DNA, photosystem, and membranes). Changes lead to activation of caspases and cell death. An important effect is a decrease in GSH concentration and consequent damage to cellular components. These complex changes result in changes in overall metabolism.

Increased use of silver nanoparticles (AgNPs) enhances the risk of their release into the ecoenvironment. There is also growing concern about health and safety risks [11]. It is therefore essential to address the potential effect of AgNPs on plants as primary producers and an essential component of the ecosystem $[4,6]$. These effects may vary depending on the size, shape and concentration of the nanoparticles. They can also be different depending on the age and type of plant. Terrestrial plants can be exposed to nanoparticles in many ways. The main ones are potential leakage into the environment, irrigation with contaminated surface water, application of contaminated biosolids, or wastewater drain [11]. However, only a very limited number of publications have so far dealt with the interaction between higher plants and AgNPs. The aim of this work was to study the effect of different concentrations of silver nitrate $\left(\mathrm{AgNO}_{3}\right)$ and AgNPs on germinated plants of maize (Zea mays) of Silen variety.

\section{Materials and methods}

\section{Chemicals}


Silver nitrate, methanol, $\mathrm{NaCl}$ and other chemicals were purchased from Merck (USA) at a purity $>99 \%$. All chemicals that we used for gel electrophoresis were purchased from VWR (Germany). All plastic materials used (tubes, tips) in this study were purchased from Eppendorf (Hamburg, Germany). Deionised water was prepared by using the reverse osmosis equipment Aqual 25 (Brno, Czech Republic), and was further purified by using an ELGA apparatus equipped with a UV lamp (Lane End, United Kingdom). The resistance was $18 \mathrm{M} \Omega$ and the $\mathrm{pH}$ was measured using the $\mathrm{pH}$ meter (WTW).

\section{Spectrometry and electrochemical measurement}

Photometry: BS-300 chemical analyzer from Mindray (China), cuvettes 5 x 6 x 30 mm, optical path $5 \mathrm{~mm}$, a volume of reaction mixture in the cuvette $180-500 \mu \mathrm{L}$. Photometric detector measuring at wavelengths: $340,405,450,510,546,578,630$, and $670 \mathrm{~nm}$. Spectrophotometry: A UV/VIS UV-3100PC, VWR (USA) single-beam spectrophotometer was used to record the UV-VIS spectra. The VIS spectrum was measured every $2 \mathrm{~nm}$ in the range of $350-700 \mathrm{~nm}$ in plastic cuvettes with an optical path of $1 \mathrm{~cm}$. The Infinite F50 (Tecan, Switzerland) was used for measurement on a polystyrene microtiter plate (Gama Group a.s., Czech Republic). Electrochemical analysis of silver was performed by DPV method, $0.2 \mathrm{M}$ acetate buffer ( $\mathrm{pH} 5)$, scan from -0.1 to $0.6 \mathrm{~V}$, polarization rate of $25 \mathrm{mV} / \mathrm{s}$ (working carbon electrode, Metrohm, Switzerland). Characterization of nanoparticle surface was performed by methods previously optimized [12-18]. Ferric Reducing Antioxidant Power (FRAP) is based on the reduction of 2,4,6-tripyridyl-s-triazine complex (TPTZ) with $\mathrm{FeCl}_{3} \cdot 6 \mathrm{H}_{2} \mathrm{O}$ and the absorbance was measured at $605 \mathrm{~nm}$. The radical of 2,2'-azino-bis(3-ethylbenzothiazoline)-6-sulfonic acid (ABTS, $7 \mathrm{mM}$ ) and potassium peroxodisulfate $(5 \mathrm{mM})$ were mixed in water. The solutions were then prepared by diluting with water in a ratio of $1: 9 \mathrm{v} / \mathrm{v}$, stored for 12 hours in the dark at $4{ }^{\circ} \mathrm{C}$ prior to use and the absorbance was measured at $660 \mathrm{~nm}$ The DMPD (N,N-dimethyl)-1,4diaminobenzene method is based on quenching the color of the radical whose absorbance is 
measured at $450 \mathrm{~nm}$. Total phenols were determined by the Folin-Ciocalteau reagent $(1.5 \mathrm{~mL}$ of reagent was mixed with $200 \mathrm{~mL}$ of the sample), in which the mixture was left at $25^{\circ} \mathrm{C}$ for 5 min followed by the addition of $1.5 \mathrm{~mL}$ of $6 \%(\mathrm{w} / \mathrm{v}) \mathrm{Na}_{2} \mathrm{CO}_{3}$. The sample was left for $90 \mathrm{~min}$ at $25^{\circ} \mathrm{C}$ and the absorbance was measured at $725 \mathrm{~nm}$. Concentration dependence of gallic acid was prepared. The total flavons content was determined by the following procedure: $0.5 \mathrm{~mL}$ of the sample was mixed with $1.5 \mathrm{~mL}$ of methanol, $0.1 \mathrm{~mL}$ of $10 \%$ aluminium chloride, $0.1 \mathrm{~mL}$ of $1 \mathrm{M}$ potassium acetate and $2.8 \mathrm{~mL}$ of water. The resulting solution was left at $25{ }^{\circ} \mathrm{C}$ for 30 min and the absorbance was measured at $415 \mathrm{~nm}$. The quercetin calibration dependence was prepared to determine the concentration of quercetin. Total protein was determined by biuret $(510 \mathrm{~nm})$ and pyrogallic method $(520 \mathrm{~nm})$.

\section{Surface morphology of the nanoparticles}

Surface morphology of the nanoparticles was investigated with field emission scanning electron microscopy (FESEM) using operating voltage of $10 \mathrm{kV}$ in the SEM (Zeiss) instrument. Surface charging effect was minimized by coating the samples with gold on copper stubs with a coating instrument. Transmission electron microscope (TEM) and higher resolution TEM (JEOL) were determined on a copper stub with carbon glue and coated with gold before analysis. The samples for TEM and HRTEM were placed in vials containing absolute ethanol and ultrasonicated for $10 \mathrm{~min}$. thereafter, holey/lacey carbon grids $(10 \mu \mathrm{m})$ were dipped into the vials containing the ultrasonicated samples and dried before microstructural determination.

\section{Preparation of AgNPs by green synthesis}

Silver nanoparticles were prepared using green synthesis. The sage leaves (Salvia officinalis) were purchased in single packs (50 g, Valdemar Grešík - Natura s.r.o., Czech Republic). The leaves were first homogenized by milling to a particle size of $1-2 \mathrm{~mm}$ and then extracted. The mixture was stirred in ultrapure water $\left(80^{\circ} \mathrm{C}, 60 \mathrm{~min}\right)$ at a ratio of $5 \mathrm{DW} \mathrm{g} / 100 \mathrm{~mL}, \mathrm{v} / \mathrm{w}$. The 
leachate was further centrifuged $(30 \mathrm{~min}, 4000 \mathrm{~g})$. Then filtration through filter paper $(100 \mu \mathrm{m})$ was performed. The leachate was mixed with $0.1 \mathrm{M}$ silver nitrate (1: 1$)$ and stirred on a magnetic stirrer $\left(80^{\circ} \mathrm{C}, 24 \mathrm{~h}\right)$. The particles were precipitated with methanol (1: 1) and left on a magnetic stirrer for $60 \mathrm{~min}$. After purification, the supernatant was pipetted off and the particles were allowed to dry $\left(24 \mathrm{~h}, 60^{\circ} \mathrm{C}\right.$, VWR drier, USA). The particles were dispersed in ultrasoundirradiated water at a concentration of $3 \mathrm{mg} / \mathrm{mL}$ for 40 minutes.

\section{Biological experiment}

Seeds of maize (Zea mays) of Silen variety were sprouted on cellulose wadding in cultivation boxes (Batist, Czech Republic) in an amount of $10 \times 10$ seeds and were watered by tap water (250 $\mathrm{mL}$, conductivity of $480 \mu \mathrm{S} / \mathrm{cm}, \mathrm{pH} 6.5$ ). The boxes were left for one week at lab temperature $\left(25^{\circ} \mathrm{C}\right)$. For our experiment, 7-day-old maize seedlings were selected. The plants were chosen to be uniform in size. The seedlings were after this time placed into a hydroponic system with $3 \mathrm{~L}$ of cultivation solution and with a light of $36 \mathrm{~W} / 865$, FAR of $100 \mu \mathrm{mol} / \mathrm{m}^{2} / \mathrm{s}$ with light/dark intervals of $12 \mathrm{~h} / 12 \mathrm{~h}$. $\mathrm{AgNO}_{3}$ and AgNPs were applied at 1, 50, $150 \mathrm{mg} / \mathrm{L}$. Preparation of nanoparticles for application was as follows: homogenization was achieved by ultrasound, AgNPs $(3,150,450 \mathrm{mg})$ were added into the $2 \mathrm{~mL}$ Eppendorf tubes and the tubes were supplemented with ultrapure water to their $2 \mathrm{~mL}$ volumes. Then, three various concentrations $(1,50,150 \mathrm{mg} / \mathrm{L})$ of silver nitrate solution were prepared. Silver nitrate was used as a positive control. Silver nitrate $(3,150,450 \mathrm{mg})$ was added to Eppendorf tubes. Distilled water was used as a negative control.

\section{Analysis of photosynthetic dyes}

To determine the number of chlorophylls, $1 \mathrm{~g}$ of the above-ground portion of the plant was weighed, placed in a mortar and grinded with sea sand. Then, $1 \mathrm{mg}$ of magnesium oxide was added and, after a short period of grinding, $10 \mathrm{~mL}$ of acetone was added. The sample was 
filtered through filter paper (with $100 \mu \mathrm{m}$ pore size). The filtered sample was refilled with acetone to a $25 \mathrm{~mL}$ volume of volumetric flask. The extracted chlorophyll was diluted into a 2 $\mathrm{mL}$ glass cuvette with acetone at a ratio of 1: 9. Chlorophyll measurements were performed in the range 350-650 nm, scan $2 \mathrm{~nm}$ (UV-3100PC spectrophotometer; VWR International, USA).

\section{Physiological and morphological evaluation}

Stem (length, number of leaves) and root (length of longest and shortest root, number of roots) morphology in the plants was observed $(n=5)$. The amounts of chlorophyll, silver, protein and phenolic compounds were determined $(n=3)$. In addition, quantification and analysis of the morphological parameters of the root system (microscopic and photographic evaluation) were performed. For determining the fresh weight (FW), plants were weighed (Boeco, Germany) immediately after removal from the hydroponic system and placed on filter paper $(n=4)$. For the determination of dry matter (DW), the plants were divided into smaller parts and left for 48 h at $60{ }^{\circ} \mathrm{C}(\mathrm{n}=3)$.

\section{Microscopic and photographic analysis}

To evaluate the effect induced by $\mathrm{AgNO}_{3}$ and $\mathrm{AgNPs}$, the plants were photographed (Canon, FulHD 20.3 Mpx). Microscopic analysis was performed using a computer-connected microscope VisiScope (VWR, USA) allowing photos collection (10 MPx) on a PC. Image analysis was performed by ColorTest (Prevention Medicals, Czech Republic).

\section{Statistical evaluation of data}

Experimental work was performed in at least three independent experiments. Each sample in the experiments was analysed at least five times. The obtained data presented in this paper are the average values. No experimental points were excluded from the proposed experimental study. All the obtained data were stored in the Qinslab database (Prevention Medicals, Czech Republic). If possible, data were processed and evaluated mathematically and statistically in 
the Qinslab database. The results were expressed as mean \pm standard deviation (SD). Photos were processed by the ColorTest program, which assigns an intensity to the individual pixels of the studied image in a given color area [19]. For preparing the publication, the data were processed using MICROSOFT software (USA).

\section{Results and discussion}

\section{Characterization of prepared plant extracts from $S$. officinalis leaves}

The total protein content of extracts measured using pyrogallol red decreased with increasing temperature applied for extract preparation (from 85 to $55 \mathrm{~g} / \mathrm{L}$ ). Using the biuret test, the highest protein content $(93.5 \mathrm{~g} / \mathrm{L})$ was found in the extract prepared at $20^{\circ} \mathrm{C}$. The concentration of phenolic compounds in the extracts increased directly in proportion to the preparation temperature of the phytoextract $(3-5 \mathrm{mg} / \mathrm{L})$. The content of flavonoids in extracts obtained from S. officinalis increased with extraction temperature (from 1 up to $5.5 \mathrm{mg} / \mathrm{L}$ ). Based on the DPPH method, free radicals $(10.5 \mathrm{GA} \mathrm{g} / \mathrm{L})$ were most quenched by sage leaf extracts prepared at $80^{\circ} \mathrm{C}$. Using the ABTS method, the ability of extracts to quench free radicals was significantly reduced with increasing preparation temperature. The color evaluation of the prepared extracts at different temperatures indicated that the color intensity decreased with increasing temperature applied for the preparation of the extract. At the highest temperature used, the color intensity decreased by $15 \%$ compared to the lowest preparation temperature.

The prepared extract was mixed with silver nitrate $\left(1: 1,500 \mathrm{rpm}, 25^{\circ} \mathrm{C}\right)$. AgNPs formation was monitored spectrophotometrically. The signal of around $450 \mathrm{~nm}$ in the UV VIS absorption spectrum confirmed the presence of AgNPs in the mixture [20]. AgNPs were characterized: the hydrodynamic size ranged from $20-60 \mathrm{~nm}$, the absorption spectra achieved maximum peak at $455 \mathrm{~nm}$. AgNPs formation rate constants were determined by the integration method and were experimentally around $0.3 \mu \mathrm{M} / \mathrm{s} / \mathrm{AU}$. AgNPs were produced most rapidly using an extract 
prepared at $60^{\circ} \mathrm{C}$. An ideal time was found to produce the largest amount of AgNPs in solution which ranged between 24-48 h. The yield of AgNPs produced by green synthesis using sage was $65 \%$. Simple reactions (total phenols, flavones, ability to quench free radicals, total protein) were used for basic characterization of AgNPs surface properties. Chemical properties: the ABTS method $-40-80 \%$ of control, the DPPH method - a decrease by $15-55 \%$ after 15 min. of radical quenching, total phenols (extract): 1200-1800 mg/mL eq. GA. The SEM analysis showed that the particles were mostly spherical in shape with a size of $50 \mathrm{~nm}$. The SPR method determined the particle size at intervals of $20-60 \mathrm{~nm}$ and the zeta potential in the range of -20 to $-5 \mathrm{mV}$ (Fig. 2).

\section{The effect of AgNPs on germinated plants of Zea mays}

The interaction between AgNPs and autotrophs was studied. The uptake, translocation, and the accumulation of the AgNPs in cells depend on the cellular structure, its permeability, size of the nanoparticles [8]. The soil particles are surrounded by water potential gradients that affect plant root growth (due to positive hydrotropism, the growth of the roots is directed towards the water) and thus also the nutrient intake. Hydropatterning changes the distribution of root hairs and lateral roots along the root circumference. It has recently been discovered that the transcription factor ARF7 activates the LDB16 gene, which induced the initiation of lateral roots formation when water is available); see in Fig. 1. These recent molecular findings can bring new information on the NPs $[10,21]$. The plants were exposed to $\mathrm{AgNO}_{3}$ and $\mathrm{AgNPs}(0$, 50 and $150 \mathrm{mg} / \mathrm{L}$ ). The plants were collected on days 4,5 and 6 of the experiment. With increasing concentrations of $\mathrm{AgNO}_{3}$ and $\mathrm{AgNPs}$, significant growth retardation, discoloration and leaf tip drying have been monitored. Fig. 3 shows the dependence of the mean length and weight of plant biomass on the variants tested (control, $\mathrm{AgNO}_{3}, \mathrm{AgNPs}$ ). Plant biomass with increasing concentration and exposure day decreased. For all studied variants, the effect on the root system was noticeable. With increasing concentrations of applied amounts of $\mathrm{AgNO}_{3}$ and 
AgNPs, the roots became slightly brown. The overall reduction in plant biomass was due to plant stress response. The plant probably needed energy and substances to transport and inhibit heavy metals. The increased root biomass is probably related to ensuring an equalized water balance of plants.
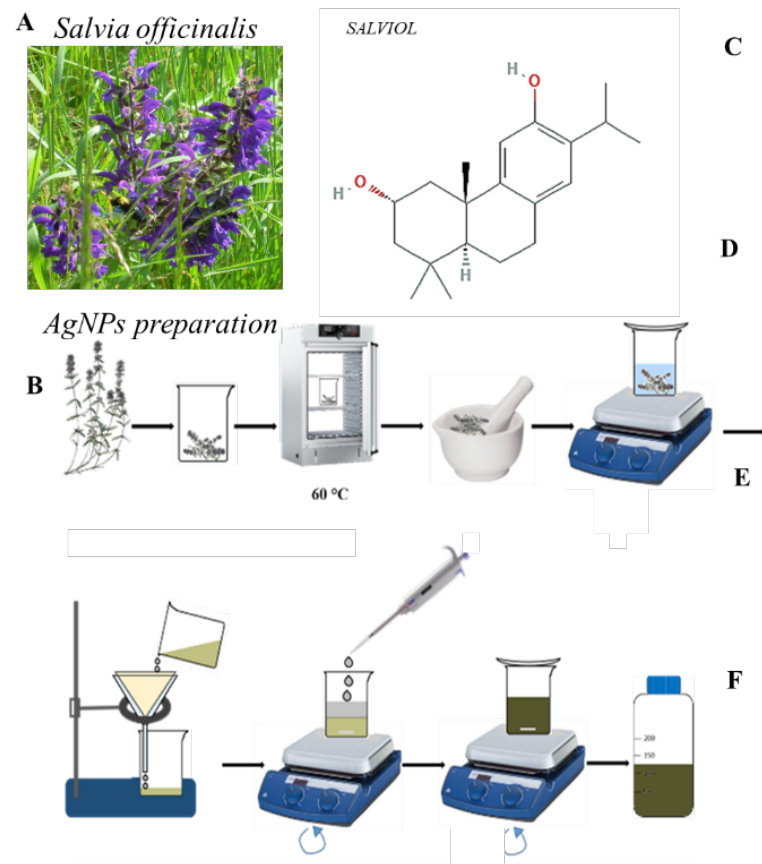
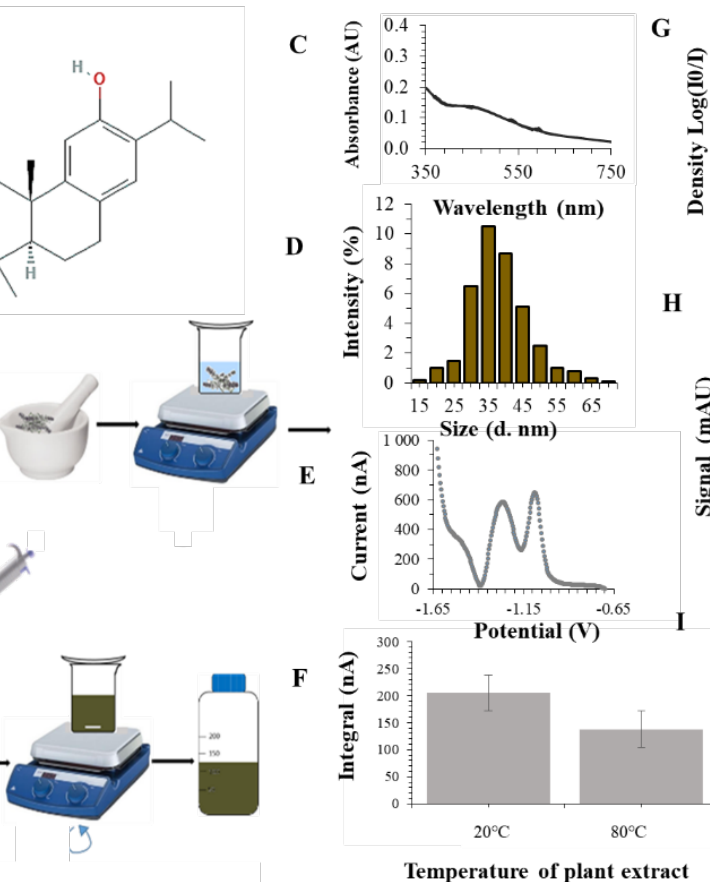
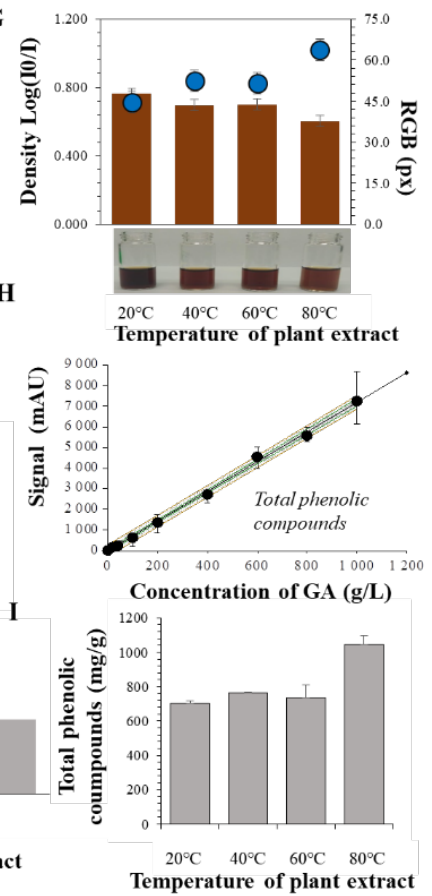

Fig. 2. Synthesis and characterization of silver nanoparticles (AgNPs). (A) Salvia officinalis was collected in the Boskovice wake in summer 2018, the plant was dried and homogenized. Its significant secondary metabolite with an antibacterial effect is salviol. (B) A simplified scheme for preparing AgNPs: The plant was washed in distilled water, dried at $60^{\circ} \mathrm{C}$, homogenized to $1 \mathrm{~mm}$ particle size, mixed with water and extracted at different times and temperatures. The extract was filtered and stirred with $\mathrm{AgNO}_{3}$. (C) $\mathrm{AgNPs}$ have been prepared and then characterized. Typical VIS spectrum of the AgNPs prepared (scan $0.2 \mathrm{~nm}$ ), (D) hydrodynamic size, (E) typical voltammogram of thiol compounds bound to the surface of AgNPs, (F) changes in integrals of thiol compounds of AgNPs prepared at 20 and $80^{\circ} \mathrm{C},(\mathbf{G})$ a typical appearance of $\mathrm{AgNPs}$ obtained using a plant extract prepared at $20,40,60$, and $80^{\circ} \mathrm{C}$. The color intensity was evaluated by ColorTest, $(\mathbf{H})$ a typical dependence of total phenolic compounds on the GA concentration, (I) total phenolic compounds of AgNPs obtained at 20, 40, 60 , and $80^{\circ} \mathrm{C}$.

Biological effects of AgNPs on maize plants - growth characteristics 
The length of the longest root was measured for each sample. Its mean length was $12.7,8.7$ and $9.9 \mathrm{~cm}$ in the control sample, in the presence of $\mathrm{AgNO}_{3}$ and in the presence of $\mathrm{AgNPs}$, respectively. Another observed parameter was the length of the above-ground portion of the plants. Its mean length was $15.9,10.8$ and $11.6 \mathrm{~cm}$ in the control sample, in the presence of $\mathrm{AgNO}_{3}$ and in the presence of AgNPs, respectively (growth reduction of about 40\%). Subsequently, the average number of roots was counted. There were no differences among group means (control 7.4; $\mathrm{AgNO}_{3}$ group 7 and $\mathrm{AgNPs}$ group 7.5). Also, the fresh root weight was found. Compared to control $(246.3 \mathrm{mg})$, there was a decrease of $27.2 \%$ in the presence of $\mathrm{AgNO}_{3}$; and in the presence of AgNPs, a decrease of $17.8 \%$ was observed. We also monitored the fresh weight of the above-ground portions of plants, which was $377.3 \mathrm{mg}$ in control; for $\mathrm{AgNO}_{3}$ we recorded a decrease of $47.8 \%$ and for AgNPs a decrease of $35.6 \%$. Compared to control, statistically significant differences were found in all studied variants at $95 \%$ significance level.

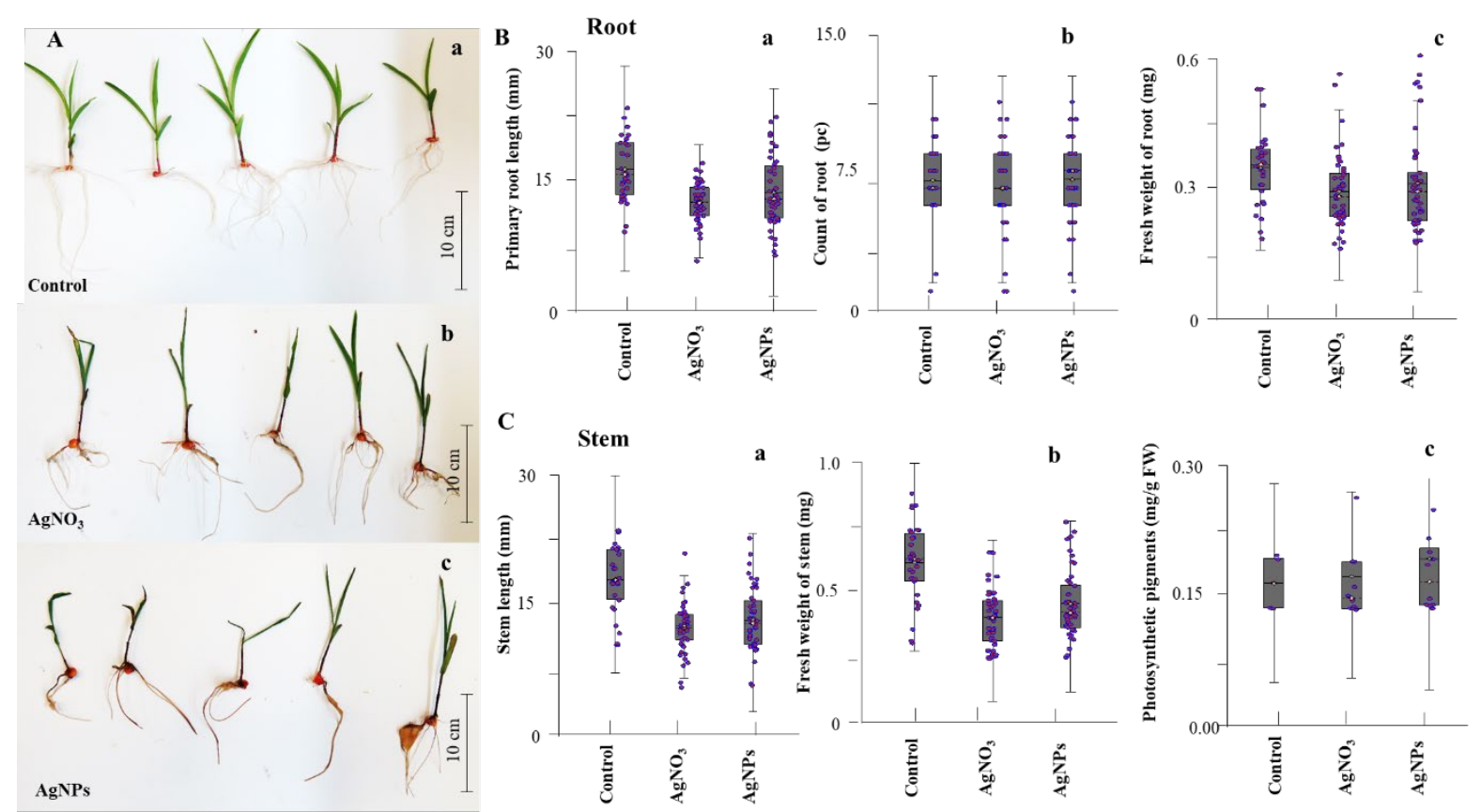


Fig. 3. Basic study of the phytotoxic effect of AgNPs on plants of Zea mays in hydroponics. (A) Typical photo of germinated plants of Zea mays - (a) control group, (b) $\mathrm{AgNO}_{3}$, (c) AgNPs - after 196 h of exposure to the hydroponic system with tap water; Ag concentration of $150 \mathrm{mg} / \mathrm{L}$. Plants were collected in triplicates every day and then processed according to the procedure described in the Material and Methods section. Statistical analysis summarizes all data on the tested variant. (B) Root analysis: (a) primary root length, (b) count of roots, (c) fresh weight of root. (C) Stem analysis: (a) stem length, (b) fresh weight of stem, (c) photosynthetic pigments. Statistical analysis was performed using Qinslab, with 95\% difference being considered to be statistically significant.

\section{Effect of AgNPs on photosynthetic pigments}

Fig. 1 shows the expected effect of AgNPs on chloroplasts and thus also on the number of photosynthetic dyes. Furthermore, the amounts of chlorophyll a, chlorophyll b, carotenes and xanthophylls were calculated by absorbance. We found that the number of photosynthetic dyes increased (control: $675 \mu \mathrm{g} / \mathrm{mL}, \mathrm{AgNO}_{3}$ group: $827 \mu \mathrm{g} / \mathrm{mL}$, and AgNPs group: $1261 \mu \mathrm{g} / \mathrm{mL}$ ). The increase in the number of photosynthetic dyes by more than $50 \%$ in the presence of AgNPs is likely caused by plant defensive reactions due to increased oxidative stress. However, this possible link should be further studied carefully [22]. A statistically significant difference compared with control was found in all studied variants at 95\% significance level.

\section{Conclusion}

AgNPs were prepared by green synthesis using sage and biophysically characterized. These particles were subsequently tested for their phytotoxicity in germinated plants of maize. AgNPs were chemically stable throughout the experiment and exhibited a number of biological effects in most of the analyzed parameters, however, these need to be further investigated.

\section{Acknowledgment}


The work was carried out with the support of the H2020 CA COST Action CA15114, INTER-

COST LTC18002. The author would like to thank Aneta Surovikova for helping with text processing and performing experiments.

\section{References}

[1] M. Akter et al., "A systematic review on silver nanoparticles-induced cytotoxicity: Physicochemical properties and perspectives," J. Adv. Res., vol. 9, pp. 1-16, 2018/01/01/ 2018.

[2] B. Fadeel et al., "Advanced tools for the safety assessment of nanomaterials," (in English), Nat. Nanotechnol., Article vol. 13, no. 7, pp. 537-543, Jul 2018.

[3] M. A. Doody, D. J. Wang, H. P. Bais, and Y. Jin, "Differential antimicrobial activity of silver nanoparticles to bacteria Bacillus subtilis and Escherichia coli, and toxicity to crop plant Zea mays and beneficial B. subtilis-inoculated Z. mays," (in English), J. Nanopart. Res., Article vol. 18, no. 10, p. 19, Oct 2016, Art. no. 290. Journal of Nanoparticle Research

[4] Y. L. Zheng et al., "Effects of silver nanoparticles on nitrification and associated nitrous oxide production in aquatic environments," (in English), Sci. Adv., Article vol. 3, no. 8, p. 11, Aug 2017, Art. no. e1603229.

[5] J. Yao, M. Yang, and Y. X. Duan, "Chemistry, Biology, and Medicine of Fluorescent Nanomaterials and Related Systems: New Insights into Biosensing, Bioimaging, Genomics, Diagnostics, and Therapy," (in English), Chem. Rev., Review vol. 114, no. 12, pp. 6130-6178, Jun 2014.

[6] S. Jafari, D. Davoodi, P. Jonoubi, A. Majd, H. Alizadeh, and Z. S. Shobbar, "Anatomical assessment of maize (Zea mays L.) seedlings exposed to colloidal silver nanoparticles," (in English), Appl. Ecol. Environ. Res., Article vol. 16, no. 3, pp. 2391-2401, 2018.

[7] P. Singh, Y.-J. Kim, D. Zhang, and D.-C. Yang, "Biological Synthesis of Nanoparticles from Plants and Microorganisms," Trend. Biotech., vol. 34, no. 7, pp. 588-599, 2016.

[8] D. K. Tripathi et al., "Uptake, Accumulation and Toxicity of Silver Nanoparticle in Autotrophic Plants, and Heterotrophic Microbes: A Concentric Review," (in English), Front. Microb., Review vol. 8, no. 7, 2017-January-26 2017.

[9] R. M. Thangavelu, D. Gunasekaran, M. I. Jesse, M. R. S.U, D. Sundarajan, and K. Krishnan, "Nanobiotechnology approach using plant rooting hormone synthesized silver nanoparticle as "nanobullets" for the dynamic applications in horticulture - An in vitro and ex vitro study," Arab. J. Chem., vol. 11, no. 1, pp. 48-61, 2018/01/01/ 2018.

[10] R. F. H. Giehl and N. von Wiren, "Hydropatterning-how roots test the waters," (in English), Science, Editorial Material vol. 362, no. 6421, pp. 1358-1359, Dec 2018.

[11] L. R. Pokhrel and B. Dubey, "Evaluation of developmental responses of two crop plants exposed to silver and zinc oxide nanoparticles," (in English), Sci. Total Environ., Article vol. 452, pp. 321-332, May 2013.

[12] G. Bibi, I. Haq, N. Ullah, A. G. Muazzam, A. Mannan, and B. Mirza, "Phytochemical evaluation of naturally growing Aster tomsonii plant species," IJPIS J. Pharmacognosy Herb. Form., vol. 2, no. 9, pp. 33-39, 2012.

[13] I. Gulcin, E. Bursal, M. H. Sehitoglu, M. Bilsel, and A. C. Goren, "Polyphenol contents and antioxidant activity of lyophilized aqueous extract of propolis from Erzurum, Turkey," Food Chem. Tox., vol. 48, no. 8-9, pp. 2227-2238, Aug-Sep 2010.

[14] B. X. Ou, D. J. Huang, M. Hampsch-Woodill, J. A. Flanagan, and E. K. Deemer, "Analysis of antioxidant activities of common vegetables employing oxygen radical absorbance capacity 
(ORAC) and ferric reducing antioxidant power (FRAP) assays: A comparative study," J. Agr. Food Chem., vol. 50, no. 11, pp. 3122-3128, May 2002.

[15] L. Parejo, C. Codina, C. Petrakis, and P. Kefalas, "Evaluation of scavenging activity assessed by Co(II)/EDTA-induced luminol chemiluminescence and DPPH center dot (2,2-diphenyl-1picrylhydrazyl) free radical assay," J. Pharm. Tox. Meth., vol. 44, no. 3, pp. 507-512, Nov-Dec 2000.

[16] R. Re, N. Pellegrini, A. Proteggente, A. Pannala, M. Yang, and C. Rice-Evans, "Antioxidant activity applying an improved ABTS radical cation decolorization assay," Free Rad. Biol. Med., vol. 26, no. 9-10, pp. 1231-1237, May 1999.

[17] J. Sochor et al., "Fully automated spectrometric protocols for determination of antioxidant activity: advantages and disadvantages," (in English), Molecules, Article vol. 15, no. 12, pp. 8618-8640, Dec 2010.

[18] J. Sochor et al., "An assay for spectrometric determination of antioxidant activity of a biological extract," (in Czech), Lis. Cukrov. Repar., Editorial Material vol. 126, no. 11, pp. 416417, Nov 2010.

[19] D. Uhlirova, M. Docekalova, M. Stankova, L. Melichar, J. Ruzicka, and R. Kizek, "A diagnostic strip for determining the amount of sarcosine, creatinine and hydrogen peroxide in a biological or environmental sample," PUV Czech Republic, vol. 30831, no. 2017-33695, 2017.

[20] B. Thomas et al., "Antioxidant and Photocatalytic Activity of Aqueous Leaf Extract Mediated Green Synthesis of Silver Nanoparticles Using Passiflora edulis f. flavicarpa," (in English), J. Nanosci. Nanotechnol., Article vol. 19, no. 5, pp. 2640-2648, May 2019.

[21] B. Orosa-Puente et al., "Root branching toward water involves posttranslational modification of transcription factor ARF7," (in English), Science, Article vol. 362, no. 6421, pp. 1407-+, Dec 2018.

[22] S. M. Zheng et al., "Role of extracellular polymeric substances on the behavior and toxicity of silver nanoparticles and ions to green algae Chlorella vulgaris," (in English), Sci. Total Environ., Article vol. 660, pp. 1182-1190, Apr 2019. 